\title{
Bond strength evaluation between textiles reinforced mortar with carbon nanotubes and concrete substrate
}

\author{
Mohammad R. Irshidat ${ }^{a *}$ (B) \\ Ammar Al-Shannaq ${ }^{\mathrm{a}}$ \\ a Jordan University of Science and Technology, P.O. 3030, 22110 Irbid, Jordan. E-mails: mrirshidat@just.edu.jo, \\ ammar_shunnag@yahoo.com \\ * Corresponding author
}

http://dx.doi.org/10.1590/1679-78255796

\begin{abstract}
The influence of using carbon nanotubes to improve bond strength between textiles reinforced mortar and concrete was investigated. Forty-two specimens were tested using double-shear test to evaluate the effect of various parameters such as CNTs addition, type of textile material, bond length and width, and number of TRM layers on the bond behavior. Two types of textile: carbon and basalt fibers were used. Various bond length and width including $50 \mathrm{~mm}, 100 \mathrm{~mm}$, and $150 \mathrm{~mm}$ were considered. Three different percentages of CNTs; $0.05 \%, 0.1 \%$, and $0.2 \%$ by weight of cement, were used. The effect of CNTs addition on the mechanical strength of cement mortar and pull-off strength of TRM were also investigated. Test results showed that adding small amount of CNTs enhanced the tensile and flexural strength of cement mortar, the pull-off strength of the TRM, and the ultimate bond load between the TRM and concrete substrate. The ultimate bond load was highly dependent on the amount of added CNTs, type of textile material, geometry of the bonded area, and number of TRM layers. The SEM images showed the role of the CNTS to enhance the adhesion at the fiber-matrix interface.
\end{abstract}

\section{Keywords}

Carbon nanotubes; TRM; concrete; bond; interface

\section{INTRODUCTION}

Textile reinforced mortar (TRM) is one of the common techniques for strengthening concrete structures. These composite materials are made out of cement-based matrix and high strength continuous fibers in form of textiles. The TRM is easy to apply and have low cost, good high temperature and fire resistance (Bertolesi et al. 2014; Carozzi and Poggi 2015). Therefore, TRM represents an attractive retrofitting solution and a good alternative to the FRP composites, the most commonly used materials for strengthening concrete structures (Haddad 2019). Significant research has been carried out in the last decade to investigate the feasibility of using the TRM in several retrofitting applications such as shear and flexural strengthening of RC beams (Truong et al. 2013; Irshidat and Al-Shannaq 2018; Escrig et al. 2017; Colombo et al. 2015), confinement and seismic retrofitting of RC columns (Ortlepp and Ortlepp 2017; Ombres and Verre 2015), and shear and out of plane strengthening of masonry structures (Baloević et al. 2016; Yardim and Lalaj 2016; Bernat-Maso et al. 2015; Carozzi and Poggi 2015). The experimental investigations have shown that the effectiveness of using the TRM composites as external bonded retrofitting materials highly depends on the bond between the composites and the concrete. Therefore, it is important to investigate the bond behavior between TRM materials and concrete substrate in order to understand the force transfer mechanism from the textile fibers to the cement matrix then to the concrete. Many studies have been conducted recently to explore the bond performance of the TRM retrofitting system using beam tests, single shear tests, and double-shear tests. The results of these studies (Ismail and Ingham 2016; Bernat- 
Maso et al. 2014; Sneed et al. 2014; D' Ambrisi et al 2013; Ombres 2012; D’Ambrisi et al 2012; Awani et al. 2015) indicated that the bond between TRM composites and concrete influenced by various parameters. These parameters include the bond between single fiber and matrix, the mortar penetration inside the textile, the bond between fibers in contact with mortar and other fibers, the fibers arrangement in the textile, bond between the matrix and concrete, and the number of the TRM layers. The experimental investigations have also shown that the most common failure mode was debonding and slippage of the fibers out of the surrounding mortar. Moreover, debonding of the matrix at the interface with concrete substrate was very rarely reported (Awani et al. 2015; Raoof et al. 2016). To overcome the debonding issue and prevent premature failure thus achieve maximum utilization of the TRM retrofitting system, the adhesion at the fiber-mortar and the mortar-concrete interfaces should be enhanced. The tremendous properties of carbon nanotubes (CNTs) allow them to be one possible solution to enhance the properties of mortar matrix thus enhance the bond between TRM retrofitting system and concrete substrate. Previous studies showed that adding CNTs could enhance the mechanical strengths and durability of cement mortar and concrete (Bani-Hani et al. 2015; Shao et al. 2017). It was also reported that using CNTs could improve the bond between FRP and concrete thus improve its strengthening efficiency (Irshidat et al. 2015; Irshidat and Al-Saleh 2017a; 2017b; M. Irshidat et al. 2011; Irshidat and AlSaleh 2016; Irshidat et al. 2016). The objective of this paper is to investigate the feasibility of using CNTs to enhance the bond strength between TRM and concrete. The effect of CNTs addition on the tensile, flexural, and compressive strengths of cement mortar was firstly studied. Then, standard test method according to ASTM D7234 was performed to measure the pull-off strength of CNTs modified mortar matrix adhered to concrete substrate. Finally, the effect of CNTs addition on bond strength between TRM retrofitting system and concrete was investigated using double-shear bond test. The effect of various parameters such as bond length, bond width, textile types, number of TRM layers and CNTs percentages was studied. Scanning electron microscopy (SEM) imaging was also conducted to explore the distribution of the CNTs within the mortar and at the interfaces.

\section{Experimental program}

\subsection{Test specimens}

A total of forty two specimens were prepared and tested using double-shear bond test. Each specimen consists of concrete prism with dimensions of $150 \mathrm{~mm} \times 150 \mathrm{~mm} \times 100 \mathrm{~mm}$ and various numbers of TRM layers attached to the sides of the prism. The main investigated parameters include CNTs addition, type of textile materials, bond length and width, and number of TRM layers. Various bond length and width including $50 \mathrm{~mm}, 100 \mathrm{~mm}$, and $150 \mathrm{~mm}$ were used. The number of TRM layers was varied from one to three; made of either carbon or basalt textile fibers embedded in either CNT modified or unmodified polymeric cement mortar. The specimens were named to show the number of TRM layers, type of textile materials, length of bonded area (L), width of bonded area (W), and CNT percentage. Specimen's layout is shown in Fig. 1. Summary of test program are given in Table 1.

\subsection{Specimens preparation}

For all test specimens, prisms were casted with concrete of $42 \mathrm{MPa}$ compressive strength. The strengthening system considered in this study comprised two types of textile fiber embedded into polymeric cement mortar. The mortar was modified by adding different percentages of CNTs; $0.05 \%, 0.1 \%$, and $0.2 \%$ by weight of cement. The CNT was commercially available multi-walled carbon nanotubes in a form of waterborne dispersions (AQYACYLTMAQ0302). The compressive, tensile, and flexural strengths of the cement mortar were measured according to the ASTM C109, ASTM C190, and ASTM C348, respectively, and presented in Fig. 2. Two commercially available fibers in a shape of textile were utilized in this study. Basalt-based textile (TYFO ${ }^{\circledR}$ EP-B) with $25 \mathrm{~mm}$ opening bidirectional mesh and carbon-based textile (TYFO ${ }^{\circledR}$ EP-C) with $30 \mathrm{~mm}$ opening bidirectional mesh as shown in Fig. 3. Table 2 summarizes the properties of the textiles as obtained from the manufacturer. 

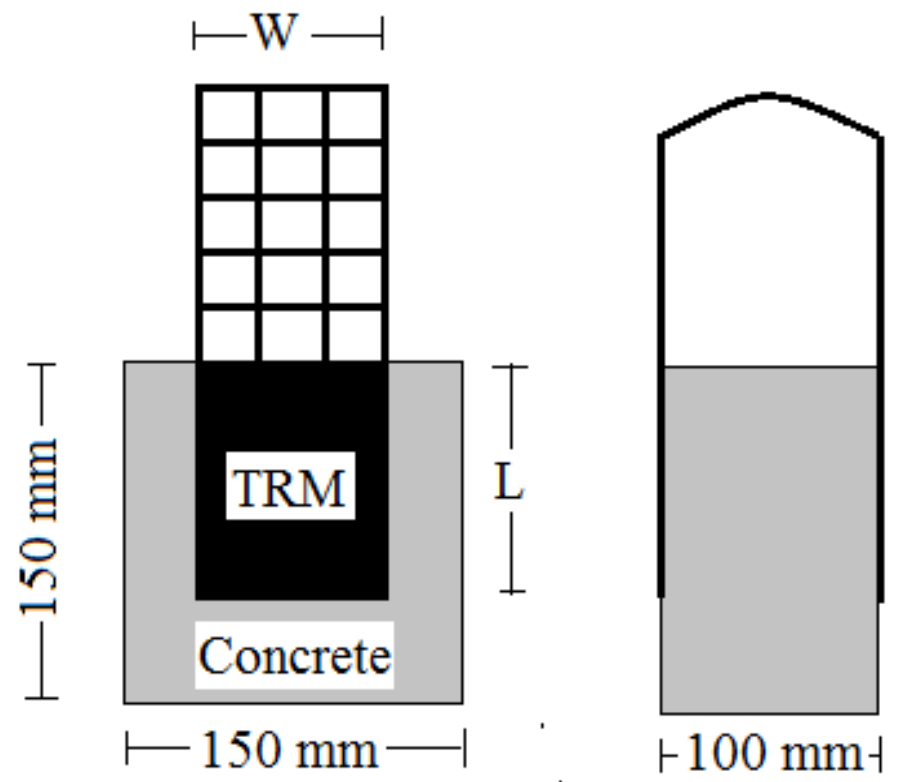

Figure 1 Double-shear test specimen layout

Table 1 Test program

\begin{tabular}{|c|c|c|c|c|c|c|c|}
\hline Designation & $\begin{array}{c}\text { No. of } \\
\text { Specimens }\end{array}$ & $\begin{array}{l}\text { No. of TRM } \\
\text { layers }\end{array}$ & $\begin{array}{l}\text { Thickness of } \\
\text { TRM layers }\end{array}$ & Textile material & $\begin{array}{l}\text { Bond length } \\
(\mathrm{mm})\end{array}$ & $\begin{array}{l}\text { Bond width } \\
\text { (mm) }\end{array}$ & CNT (\%) \\
\hline $1-C-100-100-0.0$ & 3 & 1 & $5 \mathrm{~mm}$ & Carbon & 100 & 100 & 0 \\
\hline 1-C-100-100-0.05 & 3 & 1 & $5 \mathrm{~mm}$ & Carbon & 100 & 100 & 0.05 \\
\hline 1-C-100-100-0.1 & 3 & 1 & $5 \mathrm{~mm}$ & Carbon & 100 & 100 & 0.1 \\
\hline 1-C-100-100-0.2 & 3 & 1 & $5 \mathrm{~mm}$ & Carbon & 100 & 100 & 0.2 \\
\hline 1-B-100-100-0.0 & 3 & 1 & $5 \mathrm{~mm}$ & Basalt & 100 & 100 & 0 \\
\hline 1-B-100-100-0.05 & 3 & 1 & $5 \mathrm{~mm}$ & Basalt & 100 & 100 & 0.05 \\
\hline 1-B-100-100-0.1 & 3 & 1 & $5 \mathrm{~mm}$ & Basalt & 100 & 100 & 0.1 \\
\hline 1-B-100-100-0.2 & 3 & 1 & $5 \mathrm{~mm}$ & Basalt & 100 & 100 & 0.2 \\
\hline $1-C-50-100-0.2$ & 3 & 1 & $5 \mathrm{~mm}$ & Carbon & 50 & 100 & 0.2 \\
\hline $1-C-150-100-0.2$ & 3 & 1 & $5 \mathrm{~mm}$ & Carbon & 150 & 100 & 0.2 \\
\hline $1-C-100-50-0.2$ & 3 & 1 & $5 \mathrm{~mm}$ & Carbon & 100 & 50 & 0.2 \\
\hline $1-C-100-150-0.2$ & 3 & 1 & $5 \mathrm{~mm}$ & Carbon & 100 & 150 & 0.2 \\
\hline $2-C-100-100-0.2$ & 3 & 2 & $7.5 \mathrm{~mm}$ & Carbon & 100 & 100 & 0.2 \\
\hline $3-C-100-100-0.2$ & 3 & 3 & $10 \mathrm{~mm}$ & Carbon & 100 & 100 & 0.2 \\
\hline
\end{tabular}

Table $\mathbf{2}$ Characteristics of the textiles used in this study as provided by the manufacturer

\begin{tabular}{ccc}
\hline & Basalt fiber & Carbon fiber \\
\hline Grid spacing & Bidirectional $25 \times 25 \mathrm{~mm}$ open grid & Bidirectional $30 \times 30 \mathrm{~mm}$ open grid \\
Nominal weight per square meter & $170 \mathrm{gr} / \mathrm{m}^{2}$ & $220 \mathrm{gr} / \mathrm{m}^{2}$ \\
Coated weight per square meter & $220 \mathrm{gr} / \mathrm{m}^{2}$ & $270 \mathrm{gr} / \mathrm{m}^{2}$ \\
Tensile strength (MPa) & 6.00 & 8.40 \\
Max. elongation & $1.62 \%$ & $1.68 \%$ \\
Tensile modulus (GPa) & 0.37 & 0.50 \\
Layer thickness (mm) & 5.0 & 5.0 \\
\hline
\end{tabular}




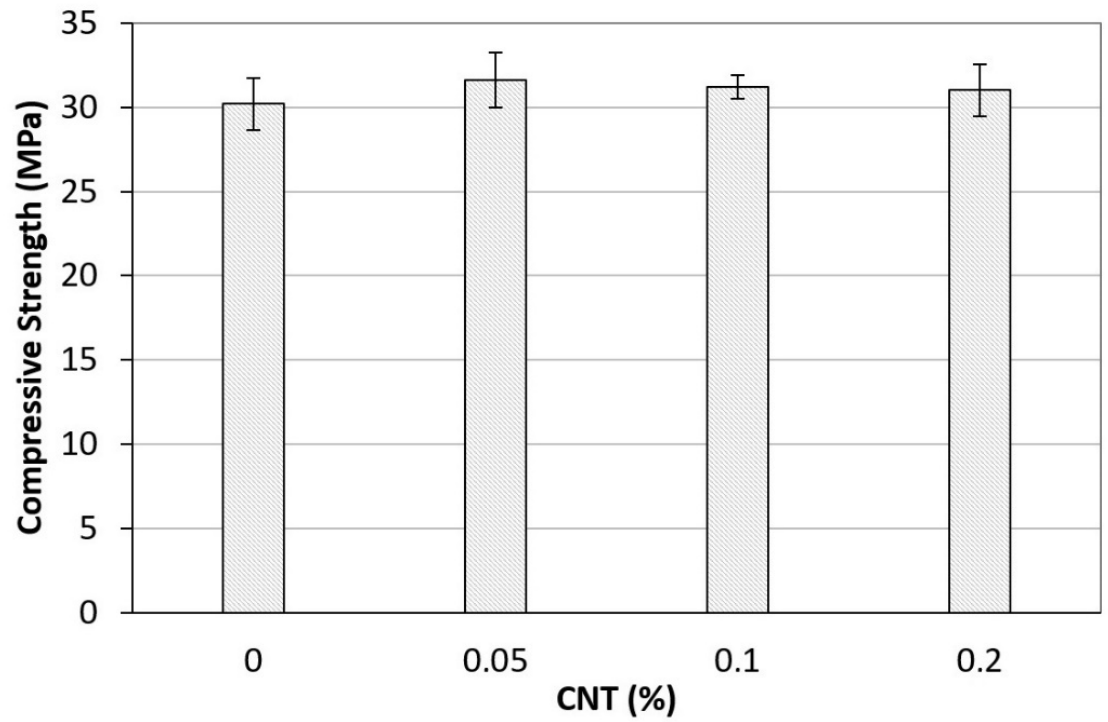

(a)

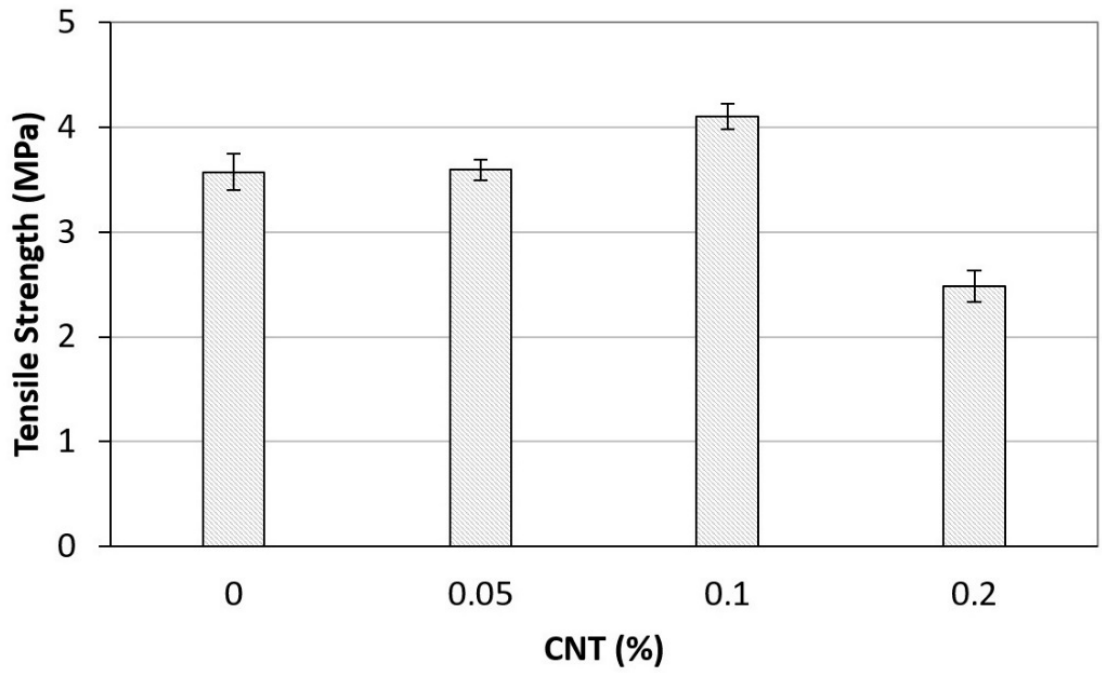

(b)

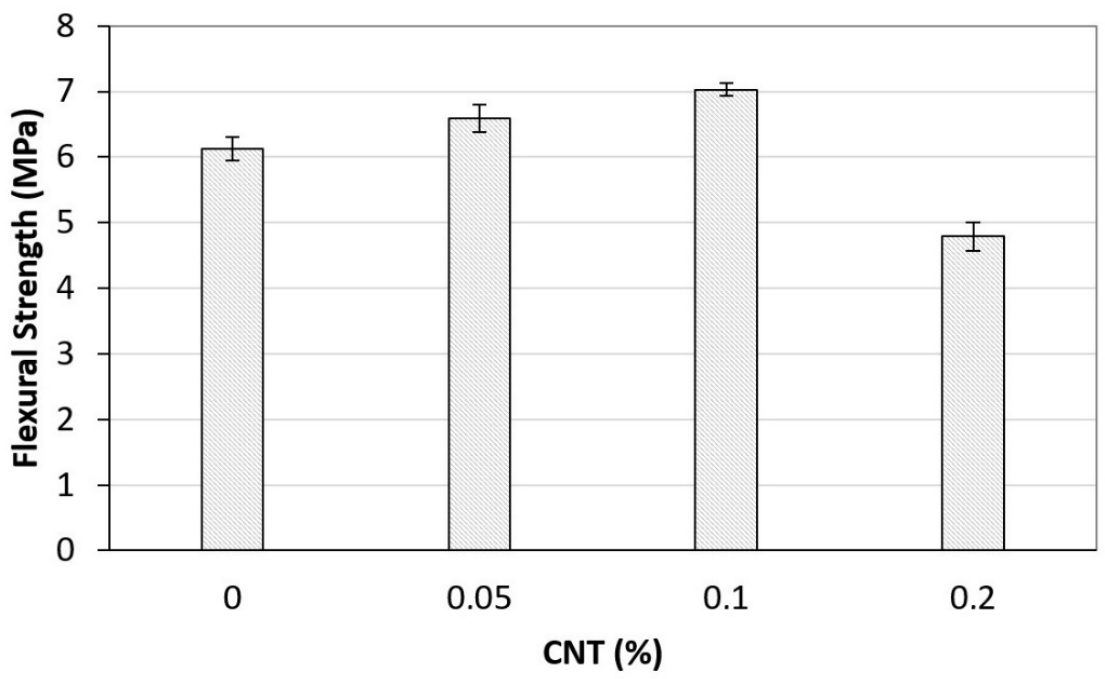

(c)

Figure 2 Mechanical strength of cement mortar (a) Compressive (b) Tensile (c) Flexural 

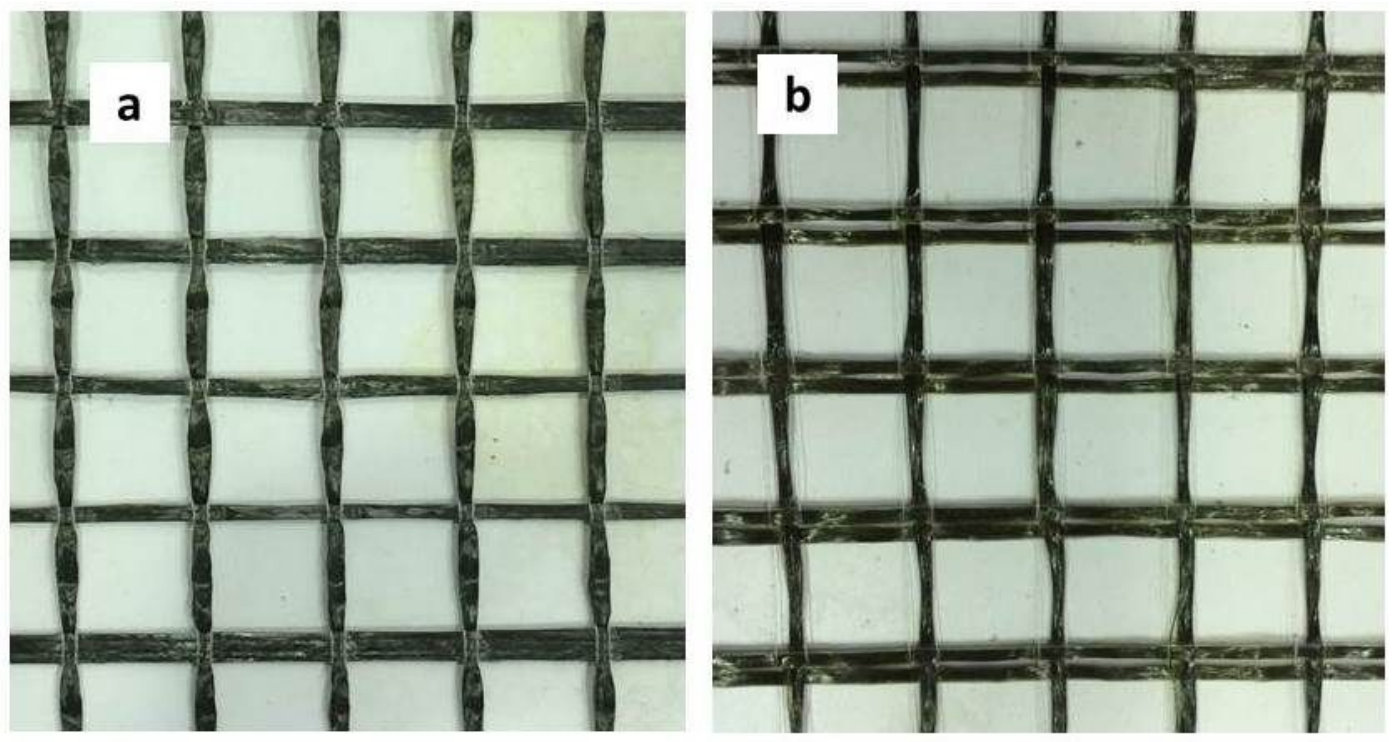

Figure 3 (a) Carbon textile (b) Basalt textile used in this study

\subsection{CNTs dispersion and specimen preparation}

Specific amount of the CNTs aqueous solution was diluted in water to get the required CNTs-percentage. The diluted solution was then stirred to get homogeneous. After that, the solution was sonicated for ten minutes to get full dispersion of CNTs in water. After that, control specimens were prepared with tap water whereas the CNTs solution was used to mix the CNTs specimens. On the other hand, to achieve sufficient adhesion between the TRM and the concrete substrate, the surface of the concrete prisms was roughened using a hammer and then cleaned. After that, the concrete surfaces were wetted for about 2 hours prior to mortar application. Then, a layer of mortar or CNT modified mortar with $2.5 \mathrm{~mm}$ thickness was applied on the surface of the prisms using a metal trowel. The textile was then pressed slightly to ensure impregnation of the fabric into the mortar. To cover the textile, another layer of mortar with $2.5 \mathrm{~mm}$ thickness was applied. Same procedure was followed to prepare each other layer of TRM. The specimens were then cured for 28 days in the lab before testing.

\subsection{Test setup}

Double-shear test was conducted to measure the bond strength between CNT modified TRM and concrete prisms as shown in Fig. 4. The test was performed with a displacement control condition under rate of $0.3 \mathrm{~mm} / \mathrm{min}$. The displacement between the TRM layer and concrete was collected using two LVDTs fixed at both sides of the specimen. The load measurements were monitored using a data acquisition system. Moreover, the microstructure at the textile/mortar interface was characterized using SEM imaging technique. In addition, standard test method according to ASTM D7234 was performed to measure the pull-off strength of mortar matrix adhered to concrete substrate. 

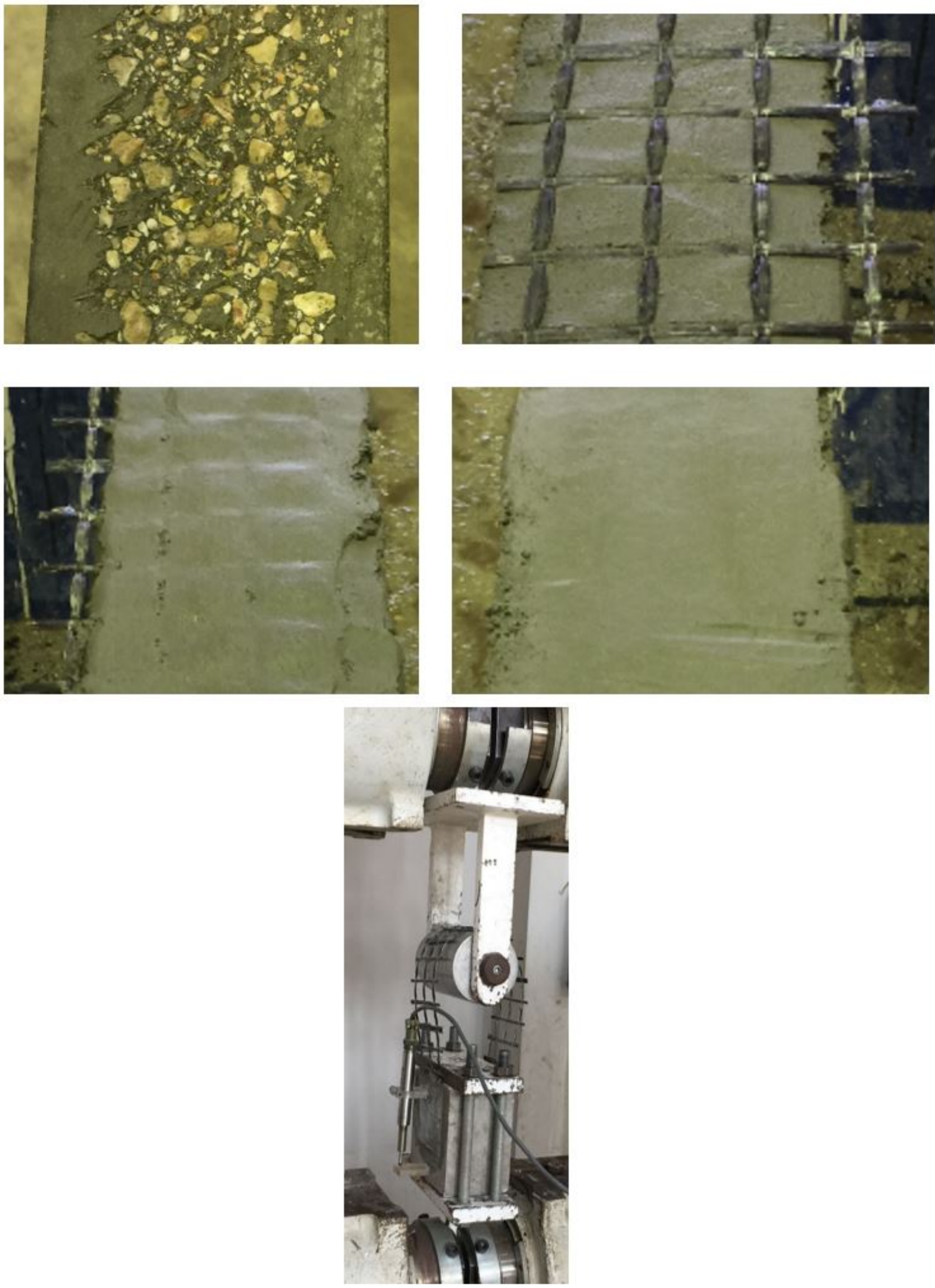

Figure 4 Specimen preparation and test setup

\section{RESULTS AND DISCUSSION}

\subsection{Mechanical strengths of CNT modified cement mortar}

The 28-day compressive strength of cement mortars with different amount of CNTs are presented in Fig. 2a. It is clear that adding $0.05 \%, 0.1 \%$, and $0.2 \%$ CNTs by weight of cement insignificantly enhance the compressive strength of 
cement mortar by $5 \%, 3 \%$, and 3\%, respectively. The difference in the strength could be attributed to the heterogeneous nature of the cementitious materials not to the CTNs addition. On the other hand, adding $0.05 \%$ CNTs did not affect the tensile strength of the mortar. Increasing the amount of CNTs to be $0.1 \%$ caused significant enhancement in the tensile strength by $15 \%$ of the control specimen strength. Further increase in the adding amount of CNTs to be $0.2 \%$ reduced the tensile strength. Similar trend was detected in the case of flexural strength. Adding $0.05 \%$ and $0.1 \%$ CNTs by weight of cement significantly enhance the flexural strength of cement mortar by $7 \%$ and $15 \%$, respectively, whereas adding $0.2 \%$ CNTs reduce the flexural strength. Similar trend was observed in the literatures (Bani-Hani et al. 2015). The improvement in the strength could be ascribed to the fact that CNTs with their small size and huge surface area filled the voids and make good bonding between the hydration products as shown in the SEM image (Fig. 5). Good dispersion of CNTs within the cement mortar is also observed in Fig. 5.

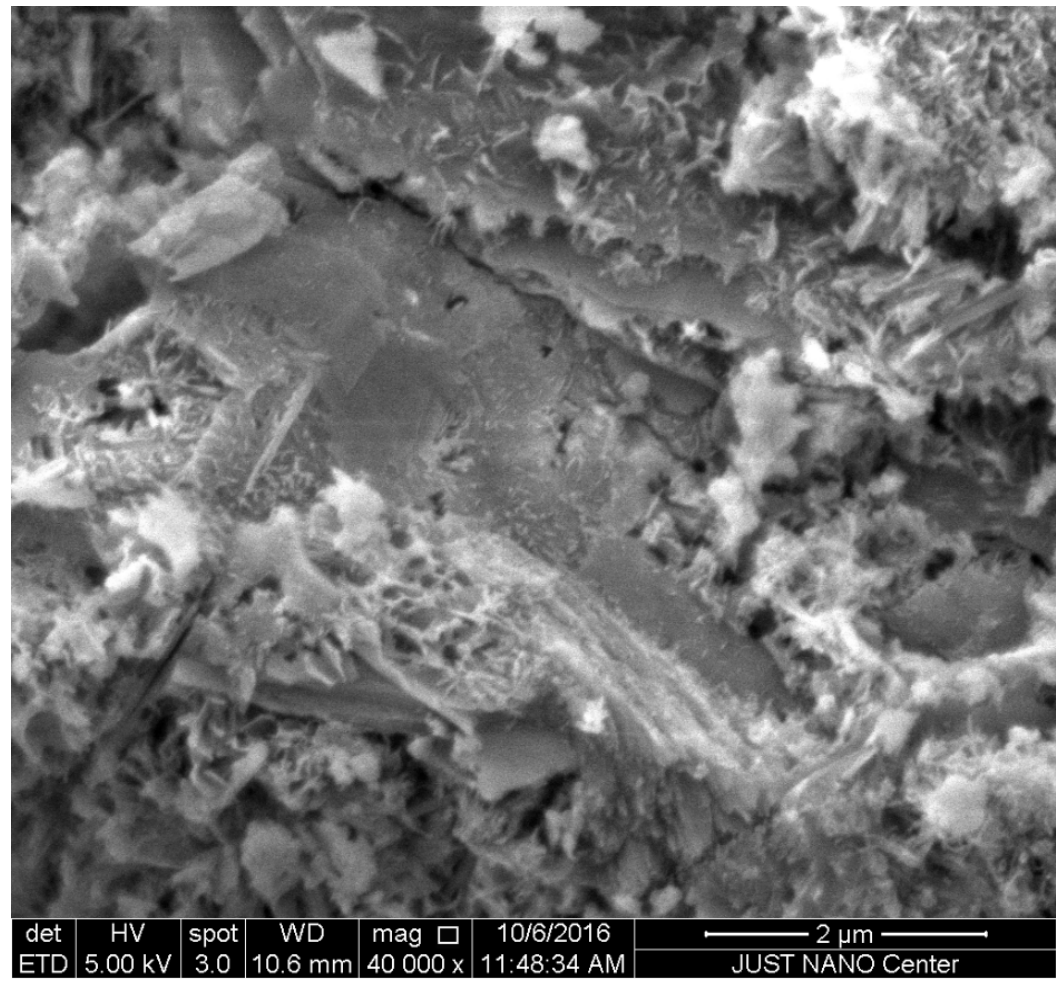

Figure 5 SEM image of CNTs dispersed in cement mortar

\subsection{Pull-off strength of CNT modified TRM}

Pull-off test is important to measure the tensile strength of the TRM after the material has been applied to the concrete surface. Fig. 6a shows the effect of CNTs addition on the pull-off strength of TRM made of two different textile fibers. The pull-off load of TRM made of one layer of carbon textile or basalt textile was equal to $0.61 \mathrm{kN}$ and $0.67 \mathrm{kN}$, respectively. Modifying the mortar matrix with CNTs enhanced the pull-off load of the TRM regardless the type of the fiber. The enhancement was increased with increasing the added CNTs. Moreover, the enhancement was noticed to be greater in the case of basalt textile than in the case of carbon textile. Adding $0.05 \%, 0.1 \%$ and $0.2 \%$ CNTs enhanced the pull-off load by $(2 \%, 18 \%$, and $39 \%)$, and $(14 \%, 39 \%$, and $70 \%)$ in the case of using carbon and basalt textile, respectively. The enhancement could be attributed to the ability of the CNTs to enhance the adhesion at the interface between the mortar and the concrete surface. In addition, the pull-off load was noticed to be increased with increasing the number of TRM layers as shown in Fig. 6b. The pull-off load of specimen 1-C-100-100-0.2 equals to $0.88 \mathrm{kN}$. In the case of using two and three layers, the pull-off load was enhanced by $11 \%$ and $23 \%$, respectively. On the other hand, the mode of failure was clearly affected by the CNTs addition. For control specimens, the failure occured between the mortar layer and concrete (Fig. 7a and Fig. 7b). For specimens with CNTs, the failure occurred in the substrate where a thin layer of concrete was attached to the mortar as shown in Fig. 7c and Fig. 7d. This finding confirmed the enhancement in the bond between the CNTs modified mortar and concrete which may be attributed to the ability of CNTs to enhance the adhesion between the mortar matrix and the concrete surfaces. Moreover, the CNTs with their small size, when being incorporated into the cement mortar, could penetrate the voids at the concrete surface thus make the interphase between mortar and concrete stronger. 


\subsection{Bond strength between CNT modified TRM and concrete}

The effect of various parameters such as CNTs addition, types of textile, bond length, bond width, and number of TRM layers were investigated. The results are reported in Table 3 and compared in terms of ultimate bond load and mode of failure. The microstructure of the fracture surfaces was investigated via SEM images. It is also important to mention that there are no slip records detected by the LVDT during the test. The specimens failed by either textile delamination or fiber slippage from the matrix. No debonding at the TRM/concrete interface.

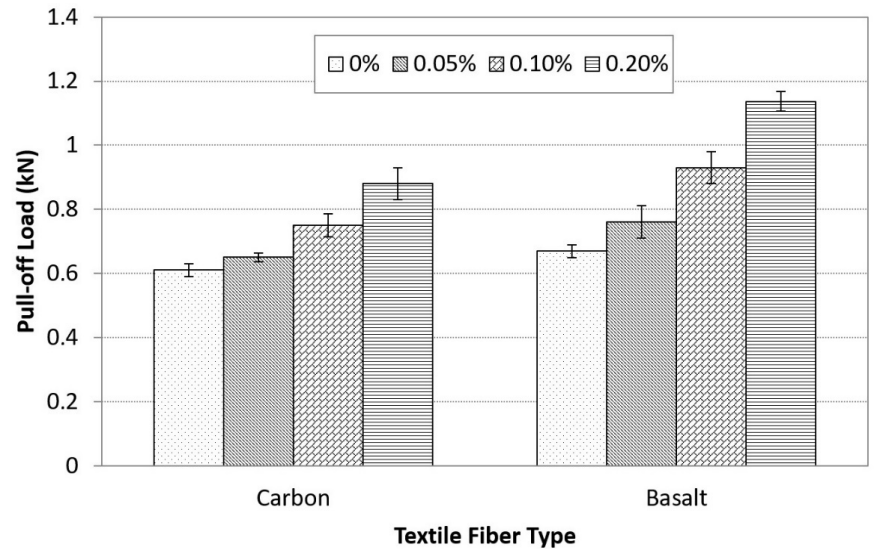

(a)

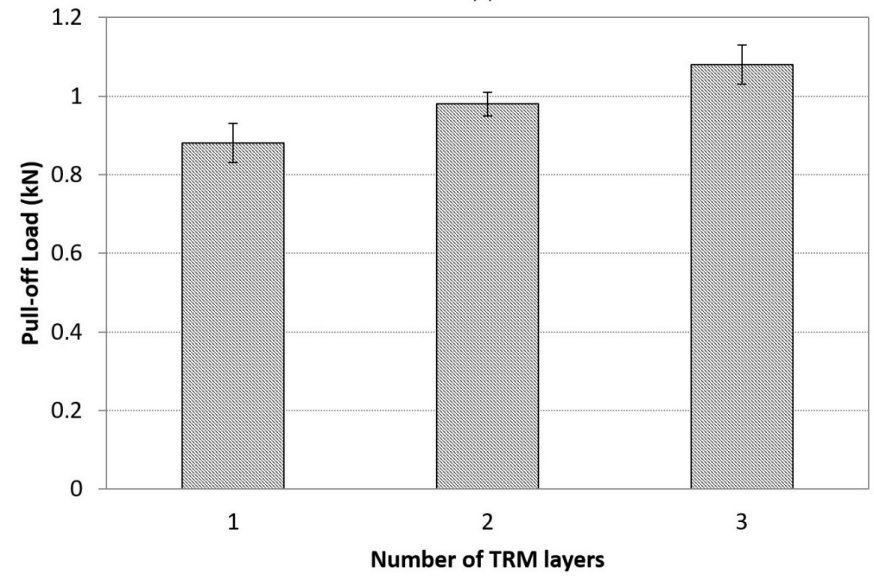

(b)

Figure 6 Pull-off strength of CNTs modified TRM (a) effect of CNTs percentages (b) effect of No. of TRM layers

Table 3 Double shear test results

\begin{tabular}{ccl}
\hline Specimen & Ultimate bond load (kN) & Mode of failure \\
\hline $1-C-100-100-0.0$ & 1.24 & Fiber slippage out of the matrix \\
$1-C-100-100-0.05$ & 1.81 & Fiber slippage with attached mortar fragments \\
1-C-100-100-0.1 & 2.19 & Fiber slippage with attached mortar fragments \\
$1-C-100-100-0.2$ & 1.77 & Fiber slippage with attached mortar fragments \\
$1-B-100-100-0.0$ & 1.75 & Fiber slippage out of the matrix \\
$1-B-100-100-0.05$ & 1.85 & Fiber slippage with attached mortar fragments \\
1-B-100-100-0.1 & 2.30 & Fiber slippage with attached mortar fragments \\
1-B-100-100-0.2 & 1.98 & Fiber slippage with attached mortar fragments \\
$1-C-50-100-0.2$ & 1.26 & Fiber slippage with attached mortar fragments \\
1-C-150-100-0.2 & 3.35 & Fiber rupture combined with textile slippage \\
$1-C-100-50-0.2$ & 1.34 & Fiber slippage with attached mortar fragments \\
1-C-100-150-0.2 & 2.58 & Fiber slippage with attached mortar fragments \\
2-C-100-100-0.2 & 3.57 & Debonding at the TRM-concrete interface \\
3-C-100-100-0.2 & 4.21 & Debonding at the TRM-concrete interface \\
\hline
\end{tabular}



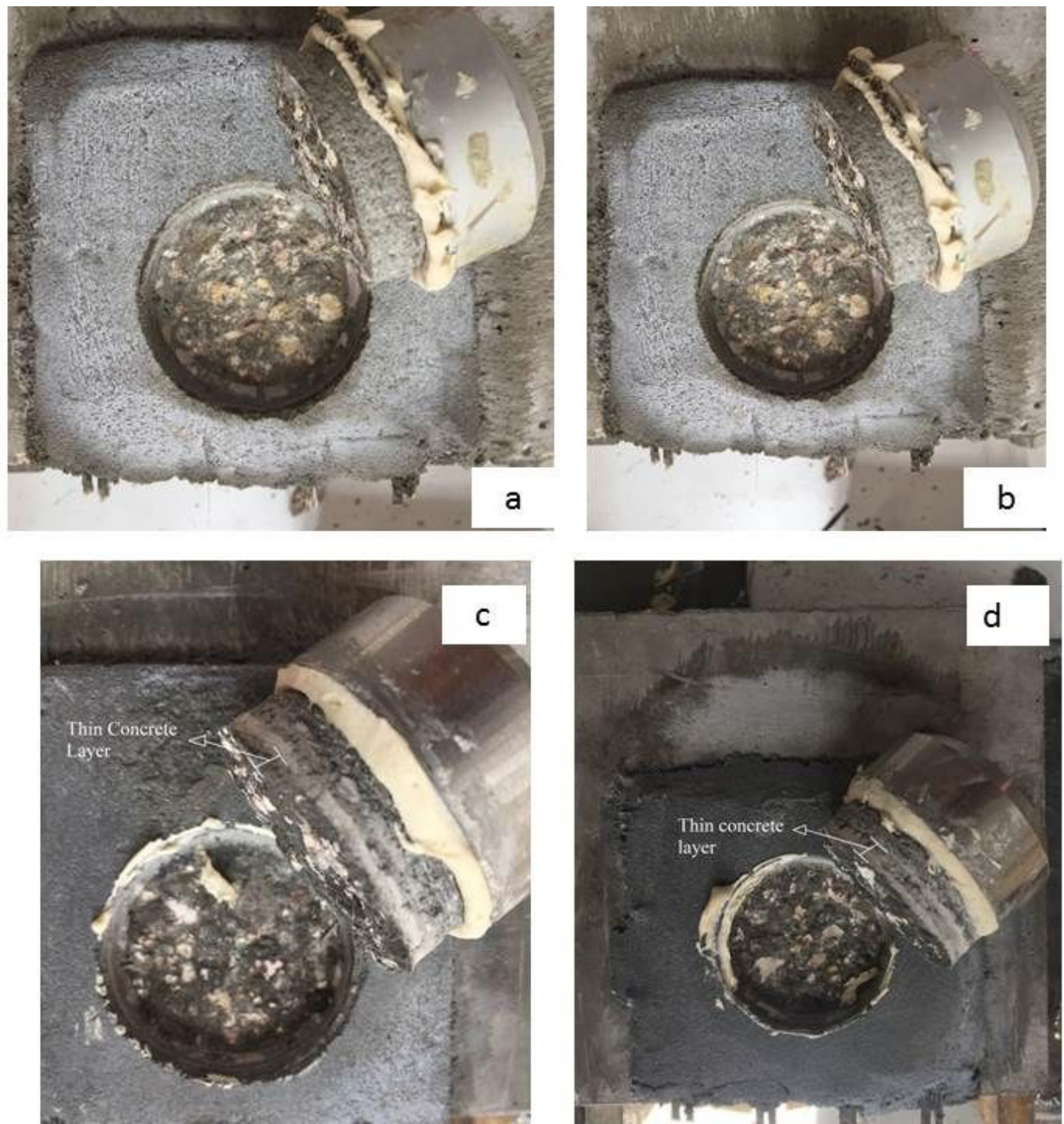

Figure 7 Failure mode of pull-off test (a) 1-C-100-100-0.0 (b) 1-B-100-100-0.0 (c) 1-C-100-100-0.2 (d) 1-B-100-100-0.2

\subsubsection{Effect of CNTs modification and type of textile}

During the test of control specimens made of carbon textile, the fabric stretched and elongation in the textile was observed. As load increased, discontinuous explosive sounds were detected indicating cracks initiation and propagation within the mortar and debonding at the fiber/mortar interface. With further load increase, control specimen (1-C-100-100-0.0) failed by slippage of the fiber inside the mortar out of the mortar until delamination of the textile occurred (Fig. 8a) at load of $2.48 \mathrm{kN}$. Same behavior was reported previously in the literatures (Awani et al. 2015; Raoof et al. 2016; Ombres 2015). Adding different percentages of CNTs to the cement mortar affected both the mode of failure and the ultimate bond load of the specimens. Specimens modified with CNTs failed by textile delamination combined with fiber slippage attached with mortar fragments as shown in Fig. 8b. This finding could reflect the enhancement in the bond between the fiber and the mortar when using CNT modified mortar compare to that of control specimen. Moreover, the ultimate bond load of CNTs modified specimens increased by $46 \%, 77 \%$, and $43 \%$ compared to the ultimate load of control specimen when $0.05 \%, 0.1 \%$, and $0.2 \%$ of CNTs were added, respectively, as shown in Fig. 9a. The enhancement may be attributed to the following reasons: Firstly, the enhancement in the mechanical strength of the mortar due to the CNTs addition as mentioned previously. Secondly, the good dispersion of the CNTs within the cement mortar at the fiber/mortar interface (Fig. 10a) and the huge surface area of the CNTs may lead to increase the contact area accordingly enhance the adhesion between the mortar and the textile as shown in Fig. 10b. The improvement in the fiber/mortar adhesion leads to enhance the load transfer between the textile and the mortar and the de-bonding load. On the other hand, control specimens made of basalt textile failed by fiber rupture at free length combined with fiber slippage out of the matrix as shown in Fig. 8c. Same mode of failure was observed in the case of using CNTs modified mortar except that mortar fragments were attached to the fibers as shown in Fig. 8d. The ultimate bond load was improved by $5 \%, 31 \%$, and $13 \%$ compared to the ultimate load of control specimens in the case of adding $0.05 \%, 0.1 \%$, 
and $0.2 \%$ of CNTs, respectively, as shown in Fig. 9a. The difference in the enhancement due to CNTs addition between carbon specimens and basalt specimens could be attributed to the difference in the mechanical properties of the textile materials and the fiber grid geometry.
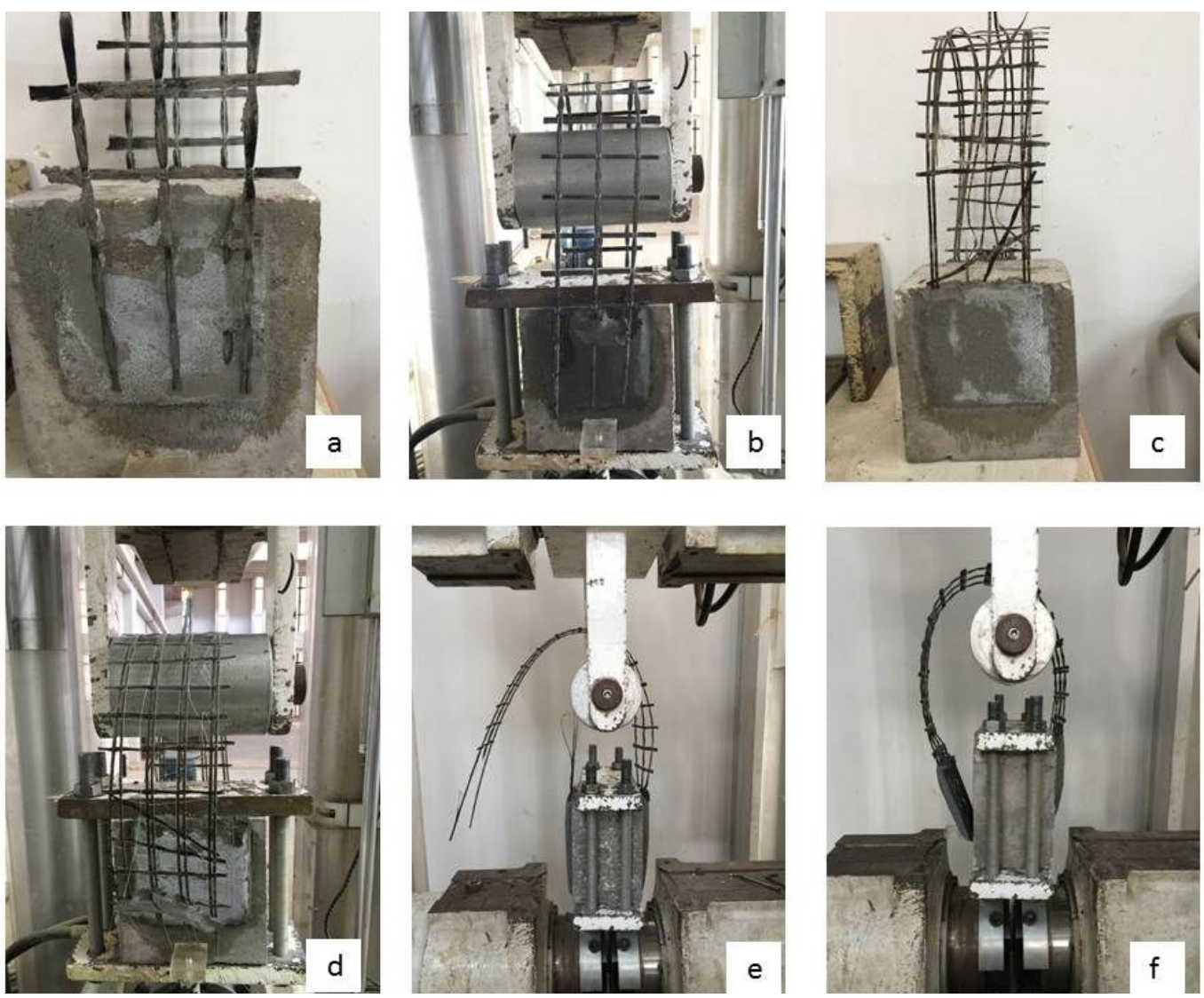

Figure 8 Failure mode of double-shear test (a) 1-C-100-100-0.0 (b) 1-C-100-100-0.1 (c) 1-B-100-100-0.0 (d) 1-B-100-100-0.2

(e) $1-C-150-100-0.2$ (f) $2-C-100-100-0.2$

\subsubsection{Effect of bond length and bond width}

Specimens strengthened with one layer of TRM made of carbon textile and mortar modified with $0.2 \%$ CNTs was tested herein. Various bond length and width including $50 \mathrm{~mm}, 100 \mathrm{~mm}$, and $150 \mathrm{~mm}$ were considered to study the effect of these parameters on the failure behavior. For the same bonded width of $100 \mathrm{~mm}$, the ultimate bond load tended to increase with increasing the bonded length. The failure load values varied from $1.26 \mathrm{kN}$ to $3.35 \mathrm{kN}$ for a bond lengths of $50 \mathrm{~mm}$ and $150 \mathrm{~mm}$, respectively, as shown in Fig. 9b. The failure mode of specimens with short bond lengths (50mm and $100 \mathrm{~mm}$ ) presented fiber slippage with little attached mortar fragments. For bond length of $150 \mathrm{~mm}$, fiber rupture was observed combined with textile slippage as shown in Fig. 8e. These results agree with the results reported in (Carozzi and Poggi 2015). The enhancement in the ultimate bond load with increasing the length of the bonded area may be credited to the increase in the length of the fiber embedded inside the CNT modified mortar. On the other hand, for the same bonded length of $100 \mathrm{~mm}$, the failure load tended to increase with increasing the bonded width. Among the tested widths, $150 \mathrm{~mm}$ offers the best results, with ultimate bond load equal to $2.58 \mathrm{kN}$ as shown in Fig. 9b. Moreover, the tests showed no influence of the bond width on the failure mode. All specimens failed by slippage of the textile out of the mortar. In addition, it is good to notice that the effect of bond length on the ultimate bond load is greater than that of bond width. For example, the alternate specimens 1-C-100-150-0.2 and 1-C-150-100-0.2 presented bond load of 2.58kN and $3.53 \mathrm{kN}$, respectively. Specimens 1-C-100-50-0.2 and 1-C-50-100-0.2 also showed similar trend.

\subsubsection{Effect of number of TRM layers}

Specimens strengthened with TRM made of carbon textile and mortar modified with $0.2 \%$ CNTs was tested herein. Different number of layers varies from one to three were chosen to study the effect of this parameter on the failure mechanism. The bond length and the bond width were kept constant at $100 \mathrm{~mm}$ by $100 \mathrm{~mm}$. As expected, the ultimate bond load increased with number of TRM layers. The failure load values varied from $1.77 \mathrm{kN}$ in the case of using one layer 
to $4.21 \mathrm{kN}$ in the case of using three layers as shown in Fig. 9c. The failure mode was also affected by number of TRM layers. In the case of using one layer, the specimens were failed by slippage of the textile. On the contrary, debonding of the TRM system from the concrete substrate was observed in the case of using two or three layers as shown in Fig. 8f.

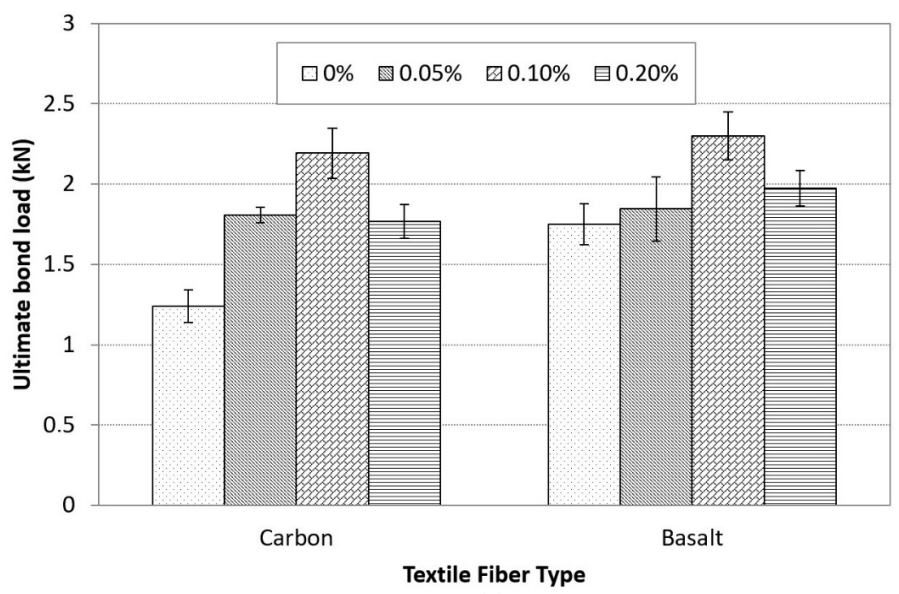

(a)

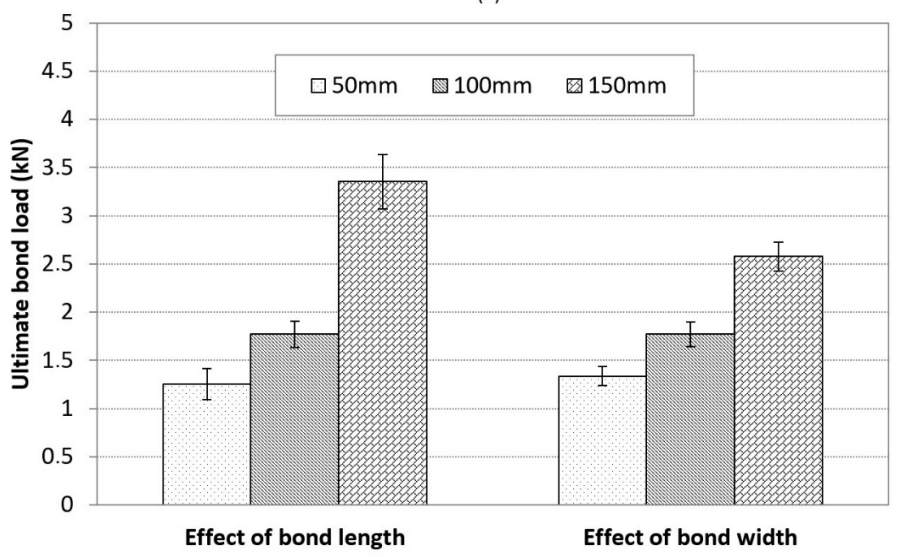

(b)

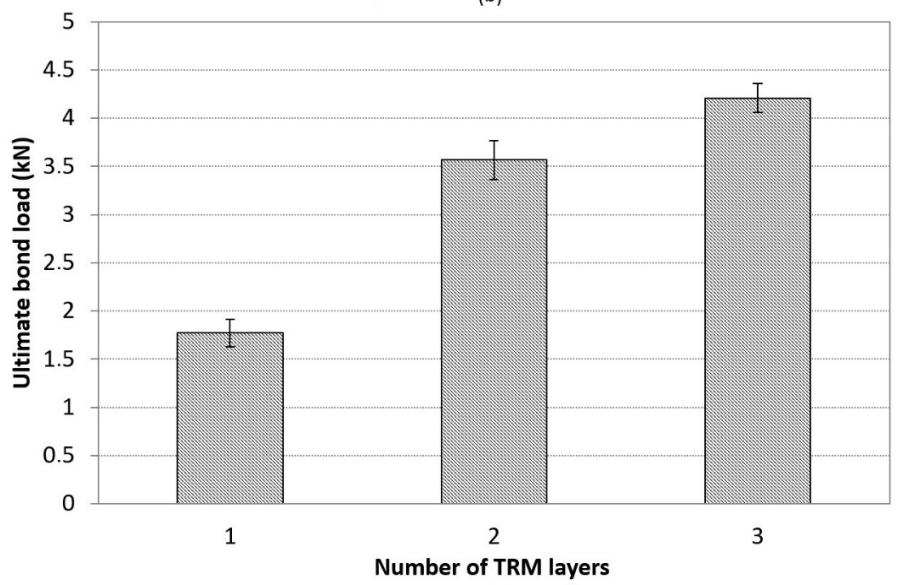

(c)

Figure 9 Ultimate bond load of CNT modified TRM (a) effect of CNT addition and textile materials (b) effect of bond length and bond width (c) effect of number of TRM layers 


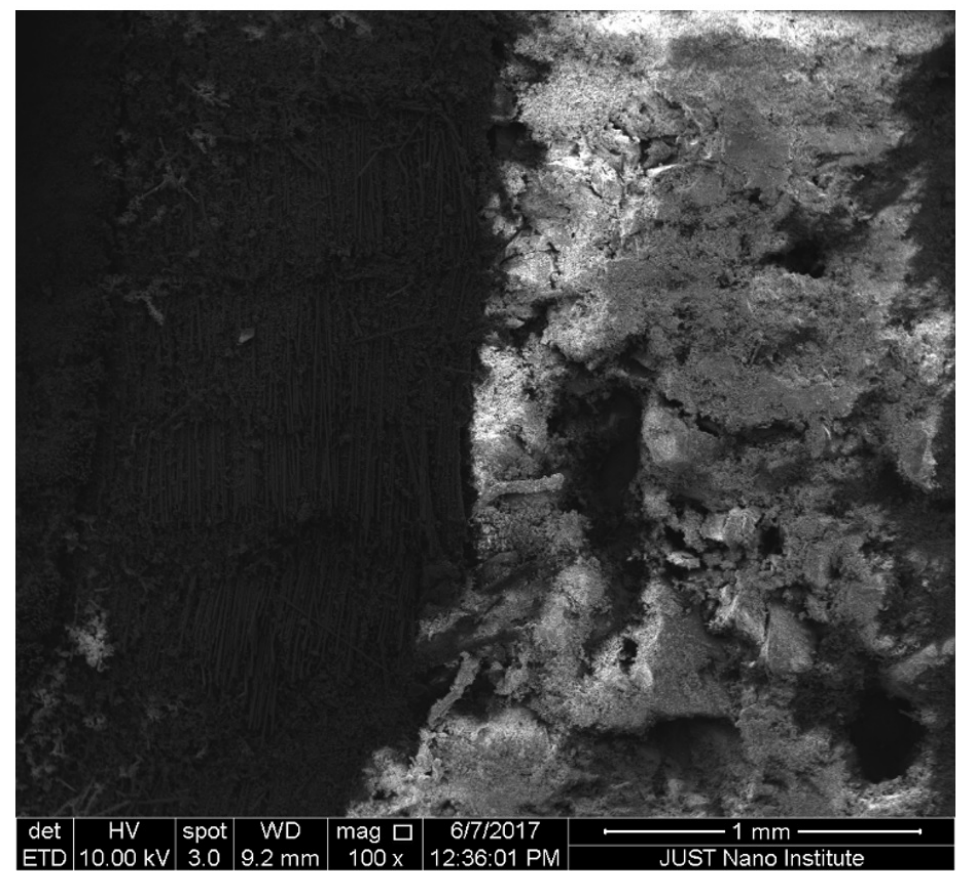

(a)

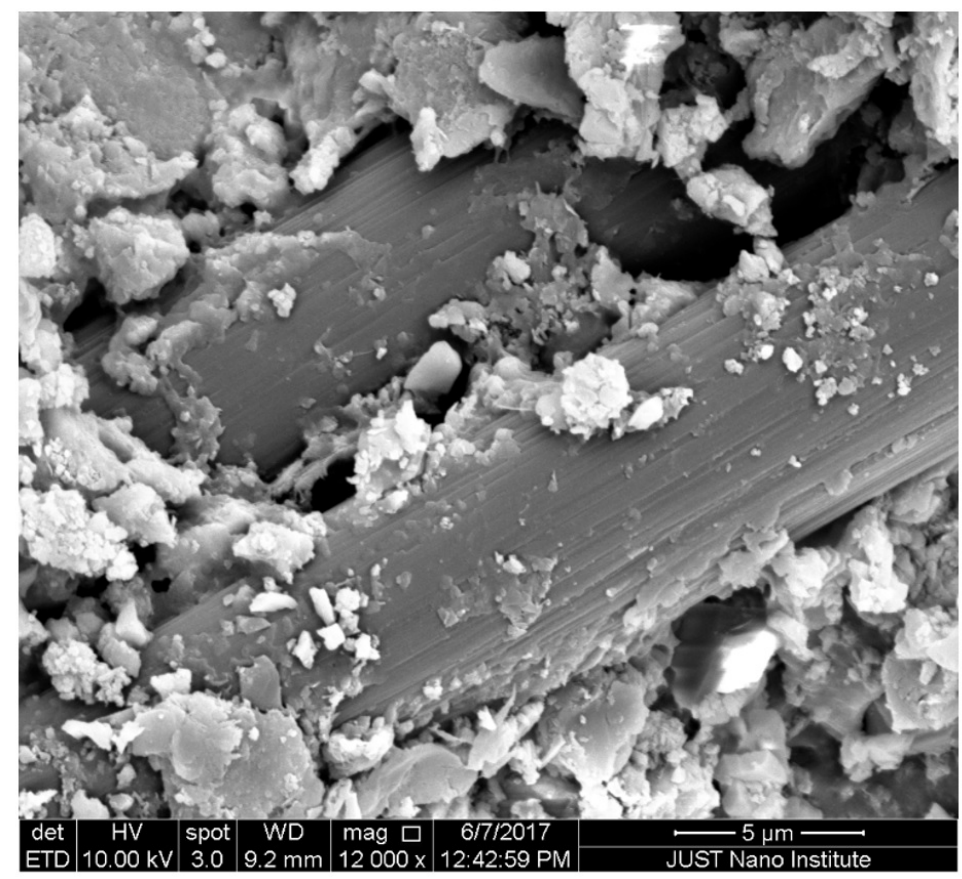

(b)

Figure 10 SEM images show (a) Fiber/CNT modified mortar interface (b) CNT modified mortar attached to the fiber

\section{CONCLUSION}

The efficiency of using carbon nanotubes to enhance the bond strength between TRM and concrete substrate was investigated. Double-shear test was performed to investigate the effect of different parameters such as CNT addition, type of textile materials, bond length and width, and number of TRM layers on the bond behavior. The influence of CNTs on the mechanical strength of cement mortar and pull-off strength of TRM was also investigated. The following conclusions could be derived:

1. Adding CNTs to the cement mortar enhanced its tensile and flexural strengths but not its compressive strength. Optimum enhancement was achieved in the case of $0.1 \%$ of CNTs. 
2. Modifying the cement mortar with CNTs enhanced the pull-off load of the TRM. The enhancement was increased with the added amount of CNTs.

3. Modifying cement mortar with CNTs affected both the mode of failure and the ultimate bond load between TRM and concrete substrate. The optimum enhancement in the bond strength was achieved in the case of $0.1 \%$ CNTs addition.

4. For the same bonded width, the ultimate bond load between CNT modified TRM and concrete tended to increase with increasing the bonded length.

5. For the same bonded length, the ultimate bond load between CNT modified TRM and concrete tended to increase with increasing the bonded width.

6. The ultimate bond load between CNTs modified TRM and concrete increased with increasing the number of TRM layers.

7. The main failure mode of the TRM due to double shear test was textile fiber delamination from the mortar. However, the mode of failure was changed to be debonding between the TRM and concrete in the case of using more than one layer.

8. SEM images showed more debris of cement mortar attached to the textile when using CNT modified mortar, which referred to the enhancement in the fiber/ mortar adhesion

\section{Acknoldgement}

The Deanship of Research at Jordan University of Science and Technology funded this work (243/2015).

Author's Contribuitions: Conceptualization, MR Irshidat; Methodology, MR Irshidat and A Al-shannaq; Investigation, MR Irshidat and A Al-shannaq; Writing - MR Irshidat; Writing - review \& editing, MR Irshidat; Funding acquisition, MR Irshidat; Resources, MR Irshidat; Supervision MR Irshidat.

Editor: Marcílio Alves.

\section{References}

Bernat-Maso Ernest, Christian Escrig, Chrysl A. Aranha, and Lluís Gil. 2014. "Experimental Assessment of Textile Reinforced Sprayed Mortar Strengthening System for Brickwork Wallettes." Construction and Building Materials 50 (January): 226-36.

Bernat-Maso Ernest, Lluis Gil, and Pere Roca. 2015. "Numerical Analysis of the Load-Bearing Capacity of Brick Masonry Walls Strengthened with Textile Reinforced Mortar and Subjected to Eccentric Compressive Loading." Engineering Structures 91 (May): 96-111.

Bertolesi Elisa, Francesca Giulia Carozzi, Gabriele Milani, and Carlo Poggi. 2014. “Numerical Modeling of Fabric Reinforce Cementitious Matrix Composites (FRCM) in Tension." Construction and Building Materials 70 (November): 531-48.

Carozzi Francesca Giulia and Carlo Poggi. 2015. "Mechanical Properties and Debonding Strength of Fabric Reinforced Cementitious Matrix (FRCM) Systems for Masonry Strengthening." Composites Part B: Engineering 70 (March): 215-30.

Colombo Isabella Giorgia, Matteo Colombo, and Marco di Prisco. 2015. "Bending Behaviour of Textile Reinforced Concrete Sandwich Beams." Construction and Building Materials 95 (October): 675-85.

D’Ambrisi Angelo, Luciano Feo, and Francesco Focacci. 2012. "Bond-Slip Relations for PBO-FRCM Materials Externally Bonded to Concrete." Composites Part B: Engineering 43 (8): 2938-49.

D’Ambrisi Angelo, Luciano Feo, and Francesco Focacci. 2013. "Experimental Analysis on Bond between PBO-FRCM Strengthening Materials and Concrete." Composites Part B: Engineering 44 (1): 524-32.

Escrig, Christian, Lluís Gil, and Ernest Bernat-Maso. 2017. "Experimental Comparison of Reinforced Concrete Beams Strengthened against Bending with Different Types of Cementitious-Matrix Composite Materials." Construction and Building Materials 137 (April): 317-29. 
Goran Baloević, Jure Radnić, Nikola Grgić, and Domagoj Matešan. 2016. "The Application of a Reinforced Plaster Mortar for Seismic Strengthening of Masonry Structures." Composites Part B: Engineering 93 (May): 190-202.

Haddad Rami. 2019. "An Anchorage System for Enhanced Bond Behavior between Carbon Fiber Reinforced Polymer Sheets and Cracked Concrete." Latin American Journal of Solids and Structures, 2019, 16(8), e22.

Irshidat Mohammad R. and Ammar Al-Shannaq. 2018. "Using textile reinforced mortar modified with carbon nano tubes to improve flexural performance of RC beams." Composite Structures 200: 127-134.

Irshidat Mohammad R. and Mohammed H. Al-Saleh. 2016. "Effect of Using Carbon Nanotube Modified Epoxy on Bond-Slip Behavior between Concrete and FRP Sheets." Construction and Building Materials 105 (February): 511-18.

Irshidat Mohammad R. and Mohammed H. Al-Saleh. 2017a. "Flexural Strength Recovery of Heat-Damaged RC Beams Using Carbon Nanotubes Modified CFRP." Construction and Building Materials 145 (August): 474-82.

Irshidat Mohammad R. and Mohammed H. Al-Saleh. 2017b. "Repair of Heat-Damaged RC Columns Using Carbon Nanotubes Modified CFRP." Materials and Structures 50 (2): 162.

Irshidat Mohammad R., Mohammed H. Al-Saleh, and Hashem Almashagbeh. 2016. "Effect of Carbon Nanotubes on Strengthening of RC Beams Retrofitted with Carbon Fiber/Epoxy Composites." Materials \& Design 89 (January): 225-34.

Irshidat Mohammad R., Mohammed H. Al-Saleh, and Mahmoud Al-Shoubaki. 2015. "Using Carbon Nanotubes to Improve Strengthening Efficiency of Carbon Fiber/Epoxy Composites Confined RC Columns." Composite Structures 134 (December): 523-32.

Ismail Najif, and Jason M. Ingham. 2016. "In-Plane and out-of-Plane Testing of Unreinforced Masonry Walls Strengthened Using Polymer Textile Reinforced Mortar." Engineering Structures 118 (July): 167-77.

Khaldoon A. Bani-Hani, Mohammad R. Irshidat, Rashid K. Abu Al-Rub, Nasser A. Al-Nuaimi, and Ala'a T. Talleh. 2015. "Strength Optimisation of Mortar with CNTs and Nanoclays." Proceedings of the Institution of Civil Engineers - Structures and Buildings 169 (5): 340-56.

M. Irshidat, A. Al-Ostaz, A. H.-D. Cheng, and C. Mullen. 2011. "Nanoparticle Reinforced Polymer for Blast Protection of Unreinforced Masonry Wall: Laboratory Blast Load Simulation and Design Models." Journal of Structural Engineering 137 (10): 1193-1204.

Oluwafunmilayo Awani, Ahmed El Refai, and Tamer El-Maaddawy. 2015. "Bond Characteristics of Carbon Fabric-Reinforced Cementitious Matrix in Double Shear Tests." Construction and Building Materials 101, Part 1 (December): 39-49.

Ombres Luciano and Salvatore Verre. 2015. "Structural Behaviour of Fabric Reinforced Cementitious Matrix (FRCM) Strengthened Concrete Columns under Eccentric Loading." Composites Part B: Engineering 75 (June): 235-49.

Ombres Luciano. 2012. "Debonding Analysis of Reinforced Concrete Beams Strengthened with Fibre Reinforced Cementitious Mortar." Engineering Fracture Mechanics, Fracture and Damage Analysis in Design, 81 (February): 94-109.

Ombres Luciano. 2015. "Analysis of the Bond between Fabric Reinforced Cementitious Mortar (FRCM) Strengthening Systems and Concrete." Composites Part B: Engineering 69 (February): 418-26.

Ortlepp Regine, and Sebastian Ortlepp. 2017. "Textile Reinforced Concrete for Strengthening of RC Columns: A Contribution to Resource Conservation through the Preservation of Structures." Construction and Building Materials 132 (February): $150-60$.

Raoof Saad M., Lampros N. Koutas, and Dionysios A. Bournas. 2016. “Bond between Textile-Reinforced Mortar (TRM) and Concrete Substrates: Experimental Investigation.” Composites Part B: Engineering 98 (August): 350-61.

Shao, Hongyu, Binmeng Chen, Bo Li, Shengwen Tang, and Zongjin Li. 2017. "Influence of Dispersants on the Properties of CNTS Reinforced Cement-Based Materials." Construction and Building Materials 131 (January): 186-94.

Sneed Lesley H., Tommaso D'Antino, and Christian Carloni. 2014. "Investigation of Bond Behavior of PBO Fiber-Reinforced Cementitious Matrix Composite-Concrete Interface." Materials Journal 111 (5): 569-80.

Truong Ba Tam, Amir Si Larbi, and Ali Limam. 2013. "Numerical Modelling of Reinforced Concrete Beams Repaired by TRC Composites." Composite Structures. Accessed May 24, 2016.

Yardim Yavuz and Ornela Lalaj. 2016. "Shear Strengthening of Unreinforced Masonry Wall with Different Fiber Reinforced Mortar Jacketing." Construction and Building Materials 102, Part 1 (January): 149-54. 